CRÍTICA, Revista Hispanoamericana de Filosofía

Vol. XXV, No. 73 (abril 1993): 3-13

\title{
CUMMINS AND CONDITIONALS
}

JANe Duran

University of California at Santa Barbara

It seems to be an odd consequence of the resurgence of interest by philosophers and psychologists in the intersection of everyday reasoning tasks and formal models that much of what philosophers have done has been misinterpreted by the social sciences.

Although work in pragmatics, sociolinguistics, anthropology and psychology itself urges concern for the relationship between the verbal and the nonverbal, many experiments within the domain of cognitive psychology have been designed as if relevant distinctions with regard to causation, conditionals and reasoning had not already been made antecedently by philosophers and linguists.

Recent work by Cummins et al. ${ }^{1}$ offers us the following conclusion:

[T] his work underscores the point make by others in the field [...] regarding the importance of ensuring that one has captured the correct formal representation of a natural language argument as represented by the reasoner when

${ }^{1}$ Denise Cummins, Todd Lubart, Olaf Alksnis and Robert Rist, "Conditional Reasoning and Causation", in Memory and Cognition, Vol. 19, No. 3, 1991, pp. 272-282. 
evaluating human reasoning performance. There is abundant evidence that people's representation of the truth conditions for certain logical statements go beyond those of first-order logic, and that the knowledge that they import into their representations of the reasoning problem is often relevant to the task of drawing true conclusions to guide behavior. ${ }^{2}$

It is intriguing that Cummins et al. employ the phrase "representations of the truth conditions for certain logical statements go beyond those of first-order logic", for most of the syllogisms with which the Cummins subjects were presented in the experimental task in question did not in fact deal with logical relationships. Rather, they dealt with causal relationships. And in spite of the fact that the philosophical literature is rife with discussions about the misuse of the material conditional in causal contexts, many social scientists continue to set up tasks in such a way that the improper use of the conditional by the experimental subjects is virtually invited.

The work of Cummins in this regard is fairly standard for the sort of task frequently constructed by psychologists in the hope of gathering information on the reasoning on conditionals. Braine and O'Brien have done similar work, and the Cummins paper has a multitude of citations of relevant experimental data. ${ }^{3}$ Unfortunately, such work often fails to make from the outset a very important distinction, that between conditionals (few in number, in mundane discourse context) which are actually structured in terms of logical relationships and where rules such as modus ponens and modus tollens genuinely hold, and conditionals (great in number in mundane discourse context) which are ac-

${ }^{2}$ Ibid., p. 281.

${ }^{3}$ Martin D.S. Braine and David P. O'Brien, "A Theory of If: A Lexical Entry, Reasoning Program and Pragmatic Principle", in Psychological Review, Vol. 98, No. 2, 1991, pp. 182-203. 
tually concerned with causal relationships and where the relevant rules do not hold because the reasoning involved is primarily or completely inductive. In setting up work on conditionals, social scientists often evince perplexity at the failure of subjects to perform well on these tasks, and alarm at the frequency with which some subjects will, for example, mistake denying the antecedent for a valid move. But the failure to distinguish between different sorts of conditionals at the outset is, I argue, one of the main components of this striking trend in experimental results, and is a phenomenon of which many psychologists appear to be insufficiently aware.

Now Cummins et al. initially appear (in the work under citation) to have made this distinction. We are told at the outset that there is a significant difference between the following two arguments:

1. If it is a dog, then it is an animal.

It is not a dog.

Therefore, it is not an animal.

2. If you mow the lawn, then I will give you $\$ 5$.

You do not mow the lawn.

Therefore, I will not give you $\$ 5$. $^{4}$

As the authors note, "Although both arguments are of the same (invalid) form (denying the antecedent), people generally find Argument 2 but not 1 acceptable.[... T This is because our prior knowledge concerning promises indicates that conditional statements like that in Argument 2 are to be interpreted as biconditionals; that is, if you mow the lawn, I will give you $\$ 5$, if you do not mow the lawn, then I will not give you $\$ 5$. Hence Argument 2 appears valid." But what is the case here, of course, is precisely

4 Cummins, in op. cit., p. 274.

5 Ibid. 
what the authors do not note: Argument 1 is an example of an argument structured in terms of actual logic relationships; Argument 2 is not. Argument 2 is an example of a common case of causally-related instances, and if (as the authors misleadingly insist) subjects generally want to interpret 2 as a "biconditional", it is because they know that, in general, when causal antecedents are not fulfilled, effects do not occur.

To be fair, it appears to be something like this distinction which is in fact the driving motive behind the research of Cummins et al., but this is a fact which is gleaned from an analysis of their experimental task, rather than stated explicitly. Still in the opening description of their task, the researchers assert that it is important to "make a clear distinction between deductive inference and pragmatic inference", 6 and they also claim that:

A pragmatic reasoning schema is a body of rules induced from life experiences that captures the proper interpretation of statements referring to classes of situations, such as permission situations, obligations, threats, and so forth. These interpretations do not necessarily correspond to those assigned to the logical (material) conditional in first-order logic. Nor should they. ${ }^{7}$

Well said, one is tempted to reply. The reason that subjects' interpretations do not necessarily correspond to those assigned to the material conditional is that the subjects are reasoning on the basis of induction, not deduction. The causal relations typically invoked in many of the syllogistic schema do not, of course, lend themselves to the use of the conditional, and most subjects intuitively understand this.

6 Ibid.

7 Ibid., p. 275. 
At a slightly later point in the introduction, Cummins et al. do employ the language of causality. But what their experimental hypothesis amounted to is fully fleshed out in the following section:

To summarize, we predicted that prior knowledge concerning alternative possibilities to the causal scenarios described by causal conditionals would influence peoples' interpretations of the conditionals.[...] More particularly, we predicted an interaction between the nature of the prior knowledge and the form of the argument on reasoning performance. Modus ponens and modus tollens were predicted to be influenced by the number of disabling conditions... ${ }^{8}$

But, of course, one wants to reply-since the relationships are not actually deductive in the first place, prior knowledge affects the subjects' response to the relationships in an inductive manner, and the intuitive use of the inductive mode (how often, for example, some "causes" are related to some "effects") would in the usual course of things affect whether the subject reasoned that the alleged relationship in the experimental structure would hold. What we have here, taken in toto, is a rather sophisticated instance of alteration to fit the facts. If the plain, pre-theoretical analysis of the situation indicates that it is erroneous to cast causal material in the mode of the material conditional, then one can hardly be surprised that subjects do not perform "well" on such conditionals, nor is it surprising that it would then be necessary to devise an experimental procedure to try to show how it is that subjects do not perform well, since what they are really doing is noticing what is obviously the case - that they are not dealing with logical relationships.

Braine and O'Brien also seem to sense that there is a difficulty around which one cannot get in attempting to

${ }^{8}$ Ibid., p. 276. 
employ the material conditional in everyday contexts; although the bulk of their work is aimed at proposing a lexical entry for "if" in certain schemas (an altogether different task), they do note that "[T]here are serious difficulties with the truth-table approach to the meaning of if, and there is general agreement that ordinary reasoning does not use truth-tables." Indeed, in the Cummins task some subjects seem to be able to come to conclusions about underdetermination, as one of the tasks the experimenters had to perform in culling 16 statements to be used for the final presentation was to disallow what they took to be "unlikely" disabling conditions ("e.g., aliens intervened"). ${ }^{10}$

Cummins et al. come to the not-so-surprising conclusion that "There is abundant evidence that people's representations of the truth conditions for certain logical statements go beyond those of first-order logic, and that the knowledge they import into their representations of the reasoning problem is often relevant to the task of drawing true conclusions to guide behavior."1l But more important, perhaps, is the fact that research such as the group undertakes is, according to their analysis, related to the vindication of mental-models work, such as that of Johnson-Laird. ${ }^{12}$ With the status of such work somewhat up for grabs in the current computational/connectionist debate, ${ }^{13}$ one cannot help but wonder what it is that this research is supposed to support.

9 Braine and O'Brien, in op. cit., p. 183.

10 Cummins, in op. cit., p. 277.

11 Ibid., p. 281.

12 Ibid., p. 280.

13 Carl Bereiter, "Implications of Connectionism for Thinking About Rules", in Educational Researcher, Vol. 20, No. 3, April 1991, pp. 10-16. 
One way of viewing conditionals reasoning tasks is to investigate the cases that are seldom investigated - the cases of actual logical relationships as instantiated in the relevant conditionals. The defect of these sorts of conditionals, of course, is that they seldom occur in mundane reasoning tasks or everyday speech. Nevertheless, they have the virtue of being actual exemplars of the material conditional relationships in which they are embedded, and of being straightforwardly rule-bound.

It is the latter point which may, indeed, be the most important with regard to the aim of the research on conditionals and other similar lines of research on apparently rule-bound activities. As noted above, some of the research seems to lend itself to the support of notions of cognition that are less than rule-bound. But it is an odd consequence of this research that if it supports some allegedly alternative model (such as Johnson-Laird's work, as indicated above), the sort of model supported - by the very nature of the task - may well be the type of model criticizable by philosophers as inherently collapsible into rule-based models. It does not seem to be possible to employ reasoning on conditionals, for example, as the sort of experimental task the results of which would lend support to models that are far away from being rule-based. It does not help any that - as I have indicated earlier - many of the tasks are set up in such a manner that the decided inappropiateness of the material conditional as an instantiation of some notion of causality is not made manifest at the opening of the experimental study.

Cummins et al. note, for example, that:

Consideration of alternatives appears to be a cornerstone in many aspects of human cognition.[...] According to all these theories, a stimulus selectively recruits its own alternatives, and these alternatives provide a rich context of remembered and constructed representations with which to 
interpret or classify the stimulus. Performance is influenced by the number of available alternatives or category exemplars. $^{14}$

But the Johnson-Laird view, for one, while relying for its impact on contrast with more overtly rule-bound accounts of reasoning tasks, ${ }^{15}$ leaves itself open to the obvious criticism that there is a great deal in the mental models view which supports the notion that the use of rules here has simply been made implicit rather than explicit. ${ }^{16}$ What one is inclined to say here is that if research on conditionals supports rule-based accounts, either implicit or explicit, one ought to get clear on which rule-based accounts are being supported, and why. ${ }^{17}$

Thus the Cummins work lends itself to a two-pronged critique, the first part of which focuses on the difficulties inherent in employing the material conditional for any causally-constructed reasoning sequences, and the second part of which addresses some of the implications for models of cognition which Cummins et al. seem to find on the basis of this research. ${ }^{18}$ The research being done on con-

14 Cummins, in op. cit., p. 280.

15 One of Johnson-Laird's chief stalking horse is L.J. Rips, "Cognitive Processes in Propositional Reasoning", in Psychological Review, Vol. 90, pp. 38-71.

16 Goldman has himself made this criticism. See Alvin Goldman, Epistemology and Cognition, Cambridge, MA: Harvard University Press, 1986, pp. 290-293.

17 In a recent ms. circulated from Princeton ("Propositional Reasoning by Model”, P.N. Johnson-Laird, Ruth M.J. Byrne, and Walter Schaeken), the second premise of a syllogism about circles reads "There isn't a circle." Johnson-Laird et al. note that "The model representing the circle must be eliminated because it is inconsistent with the premise, and the information that there isn't a circle incorporated within the one remaining model." But this is a perfect example of a step or move which seems to be implicitly rule-bound.

18 Although Cummins et al. cite some philosophers as having been 
ditionals is, according to those involved in it, important because of the light it sheds on disputes within cognition and because it, at least in some of its instantiations, appears to lend credence to those who have hypothesized cognitive models which are less than rule-based. But as Bereiter and others have argued, it is not entirely obvious what "rulebased" amounts to, and it is by no means clear how research on conditionals structured in the fashion examined here helps to adjudicate any of these disputes. ${ }^{19}$

There are other ways to do research on conditionals, ways that emphasize the extent to which working with conditionals is related to difficulties with natural language processing, rather than primarily with logical form. ${ }^{20} \mathrm{~A}$ proposal for a recent project in this area notes "An example of the kind of reasoning from text that we will be assessing and training is conditional inference (e.g., If Joe were to have the time, he would go to Mexico). Students will read a passage and will be asked the conclusions that they have drawn and whether or not alternative can be reasonably drawn as well." 21 If it is understood from the start that a reasonable expectation regarding subjects' performance is that they will not follow the model of the material conditional, natural language factors such as tense, imagi-

of help in reviewing the ms., there is a dearth of citations to the philosophical literature on causation and conditionals in the list of references. There is no citation, for example, to Ernest Sosa, Causation and Conditionals, Englewood-Cliffs, NJ: Prentice-Hall, 1970.

19 Bereiter, in op. cit., notes that the use of the term "rule", even within a research context, is terribly vague (p. 15).

20 R. Revlin and R. Duran have a précis of a forthcoming project entitled "Diagnostic and Dynamic Assessment of Comprehension and Reasoning Skills" which is illustrative of this. (University of California at Santa Barbara, Dept. of Psychology and Graduate School of Education.)

21 Ibid. 
nativeness and contextual support can be used as possible cues for subjects' performance.

The attraction of continued reliance on the material conditional and its relationships is that it embodies, in the extreme, a notion of rules and rule-regulated activity that is easy to characterize. The attraction of non-rule-based cognitive models, connectionist or otherwise, is that they seem to help us fill in the blanks on our intuitive understanding that, as Bereiter has claimed, "What the [...] research does strongly suggest, however, is that whatever the structure of cognition may be, it is of a more makeshift and inelegant kind than classical wisdom would lead us to expect." ${ }^{22}$ The material conditional appeals to us because we can talk about biconditionals and modus tollens as if these relationships had some genuine and obvious relevance to everyday discourse.

The results of a great deal of research on natural-language conditionals suggest that, in fact, they don't. Current research needs to redirect itself so that the inductive reasoning which forms the core of our everyday experience is at the forefront. Only then will we be in a position to decide whose model of cognitive activity is being vindicated or disconfirmed.

Recibido: 13 de octubre de 1992

22 Bereiter, in op. cit., p. 11. 


\section{RESUMEN}

En este artículo el trabajo de Cummins y colaboradores sobre los condicionales se analiza y critica desde dos perspectivas: la primera señala la insuficiente atención que se presta al empleo del condicional material en un contexto causal, y la segunda indica el grado en que la investigación lleva a cabo afirmaciones e implicaciones para establecer modelos de cognición no basados en reglas, tales como el de Johnson-Laird. Se cita a Bereiter y se hace referencia al trabajo de Braine y O’Brien. Como conclusión se postula que gran parte de las investigaciones sobre razonamiento de condicionales aún no toma en cuenta lo suficiente las extravagancias del lenguaje natural.

[Traducción de Gabriela Montes de Oca V.] 